\title{
Reseña bibliográfica de: Basile, T. (2019). Infancias. La narrativa argentina de HIJOS. Villa María: Eduvim. 297 pp.
}

\author{
Palabras clave: Segunda Generación - Terrorismo de Estado - Memorias - \\ Literatura
}

Keywords: Second Generation - State Terrorism - Memories - Literature

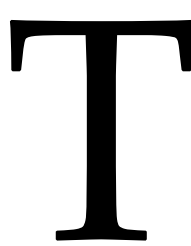

eresa Basile es Doctora en Letras, miembro del Comité Científico e Investigadora del Centro de Teoría y Crítica Literaria (IdIHCS-CONICET) y Profesora Adjunta Ordinaria en la Universidad Nacional de La Plata. ${ }^{1}$ Sus trabajos abordan los vínculos entre literatura, política y memoria en las producciones literarias de las últimas décadas. En esta oportunidad, Basile se interesa por los hijos/as de los militantes revolucionarios que también fueron víctimas de la última dictadura militar (1976-1983). Analiza sus narrativas ofreciendo un panorama exhaustivo de las producciones culturales sobre infancias atravesadas por el terrorismo de Estado. Si bien es un trabajo que aborda los procesos históricos principalmente desde la literatura, resulta una innovadora perspectiva para quienes estudiamos la historia reciente y estamos interesados en la segunda generación en la post dictadura.

La autora estudia las narrativas presentes en las producciones culturales de los hijos/as sin realizar una clasificación entre los abordajes de las ficciones, escritas o fílmicas, y las compilaciones testimoniales. En su análisis, la investigadora sostiene que existen tres líneas de interés que impregnan a las producciones culturales de los hijos/as: la narrativa humanitaria (presente en la búsqueda de sus padres y de justicia), el relato político revolucionario (referido a la reivindicación del espíritu y de la lucha revolucionaria) y la narrativa familiar (presente en las concepciones de familia desde lo político y lo afectivo).

En el capítulo I, "Las narrativas de la memoria en H.I.J.O.S e HIJOS/AS", Basile analiza el excepcional aporte cultural de la segunda generación presente en la producción de diversos formatos artísticos y en el hecho de ofrecer una perspectiva del terrorismo estatal desde la mirada infantil. Asimismo, pone el foco en las relaciones entre la agrupación H.I.J.O.S como organismo de derechos humanos, y la comunidad cultural. Basile refiere al desafío de comprender ese vínculo, entendiendo que H.I.J.O.S fue central al hacer visible y colocar en la esfera pública a la generación de hijos/as de víctimas del terrorismo de Estado, generando que de algún modo ellos deban definirse en torno al ámbito institucional de la red nacional de H.I.J.O.S. La autora reconoce la fuerte

\footnotetext{
${ }^{1}$ https://www.eduvim.com.ar/autor/teresa-basile
}

Anuario de la Escuela de Historia Virtual - Año 11 - Nº 17 - 2020: pp. 166-169. ISSN: 1853-7049. 1853-7049. http://revistas.unc.edu.ar/index.php/anuariohistoria 
impronta de la agrupación y sus marcos institucionales sobre la segunda generación en la post dictadura, pero no considera necesario encuadrar a las producciones culturales en términos de "literatura de H.I.J.O.S".

El capítulo II, "Infancia educada: el niño nuevo", está orientado al análisis de producciones literarias y documentales que dan cuenta de los proyectos educativos piloto de la izquierda revolucionaria, como el caso de "La guardería montonera" (2015) en Cuba y "El edificio de los chilenos" (2010). Basile observa cómo dichas producciones ponen el acento en las experiencias de hermandad, de afectividad y de contención de esas vivencias, así como en los procesos conflictivos que transitaron dichos niños durante el retorno a la democracia.

En el capítulo III, "Infancia clandestina: un mundo escindido", la autora pone el foco en las producciones culturales sobre las infancias de los hijos/as que vivieron en clandestinidad; es decir que analiza cómo se presenta la infancia clandestina en la literatura de la segunda generación y cómo se da cuenta de la articulación de dos mundos: el secreto y el cotidiano. Para ello, Basile construyó un corpus de textos literarios y filmes que incluye producciones como "La casa de los conejos" (2010) de Laura Alcoba e "Infancia clandestina" (2011) de Benjamín Ávila. De esta manera, la investigadora analiza las representaciones sobre la infancia y sobre los padres que se reflejan en dichas producciones observando que el conflicto parece ser el hilo central de las obras.

El eje del capítulo IV, "Infancia huérfana", es la experiencia de los hijos/as que crecieron con sus padres desaparecidos. Para ello, analiza principalmente las producciones de Félix Bruzzone y de Albertina Carri observando que es central en ellas la idea de búsqueda; es decir las experiencias de los hijos/as frente a la presencia ausencia del desaparecido, las secuelas traumáticas de la desaparición y la dificultad para construir su propia identidad. Asimismo, Basile entiende que las obras de Carri y Bruzzone resultaron un parteaguas para presentar una nueva voz de los hijos/as, centrada en relatos díscolos, que se desvían de las formas aceptadas de referir a los desaparecidos, en el descaro, el humor, la ironía y la provocación.

En el Capítulo V, "Infancia apropiada”, la autora analiza las producciones culturales que se centran en las experiencias de la vida de los hijos/as apropiados y en la restitución de su identidad. Basile refiere a la dificultad para elaborar un corpus sobre infancias apropiadas y por ello recurre a testimonios de nietos presentes en la página oficial de Abuelas de Plaza de Mayo y en las producciones del Canal Encuentro, así como algunas obras literarias como "Reencuentro. Crónica de la restitución de una identidad" (2012) de Alfredo Hoffman y fílmicas como "Botín de guerra" (2000) de David Blaustein. La autora observa cómo dichos relatos articulan diversas dimensiones involucradas en el proceso de apropiación y que remiten a lo jurídico, psicoanalítico, identitario, genético y familiar. Basile sostiene que en las producciones que narran estas experiencias se destacan dos momentos: el de la vida con los apropiadores y el de la restitución. De esta 
manera, refieren a las diferentes etapas que atraviesan dicho proceso: desde el shock inicial hasta la elaboración y la aceptación de la nueva identidad.

El capítulo VI, "Infancias violentas. Los relatos de los otros hijos", incluye relatos de los hijos/as de ex represores; es decir las infancias que no debieron lidiar con la figura del desaparecido, pero si con la del represor. En este caso, no aborda un corpus específico sino testimonios presentes sobretodo en el medio periodístico. De esta manera, Basile distingue tres tipos de memorias presentes en los hijos/as de ex represores: los que rechazan las experiencias y acciones llevadas adelante por sus padres; los que defienden y comparten el programa y el accionar de la dictadura; y aquellos que defienden a sus padres desde la legalidad, aduciendo falencias jurídicas y distanciándolos en nivel de culpabilidad respecto de otros represores. La autora destaca que la emergencia de estas nuevas voces permitió recortar la figura del represor desde el lugar de los hijos/as, introduciendo la problemática familiar y afectiva.

Finalmente, el capítulo VII, "Pasado en el presente", está orientado al análisis del sentido que le otorgan los hijos/as a la desaparición de sus padres; es decir busca dar cuenta de cómo se reflejan en sus producciones estéticas los procesos de elaboración de la desaparición. La autora busca dimensionar los aportes de los hijos/as a la representación del desaparecido y las dimensiones políticas que de ello se desprenden.

La investigación de Teresa Basile resulta un interesante aporte al estudio de la historia reciente dado que recorre diferentes modos de atravesar la infancia en el caso de los hijos/as de las víctimas del terrorismo de Estado y los visibiliza por fuera del marco institucional de los organismos de derechos humanos. "Infancias. La narrativa argentina de HIJOS" recorre las experiencias de los hijos e hijas que vivieron en clandestinidad, de los que debieron exiliarse junto a su familia, las de aquellos que fueron apropiados/as a partir del plan sistemático del Estado represor, de los que se quedaron sin sus padres debido a la desaparición forzada e incluso refiere a las vivencias de los hijos/as de los ex represores. De esta manera, la heterogeneidad de la segunda generación es puesta sobre la mesa y se problematiza un campo que suele ser simplificado en torno la militancia político humanitaria en la agrupación H.I.J.O.S o a las producciones culturales que han tenido mayor trascendencia.

El trabajo de Basile resulta un gran aporte para el campo de los estudios sobre memoria, dado que problematiza los modos en que el pasado reciente se actualiza a través de los relatos de los hijos/as. La autora permite ampliar la idea de "campo de derechos humanos" (Cueto Rua, 2008) para pensarlo no solo en términos de la legitimidad de la palabra por parte de los familiares (Jelin, 2006), sino en el sentido de "campo cultural". Esto se evidencia al ampliar la problematización de las narrativas más allá de la agrupación H.I.J.O.S y al conformar su corpus de estudio con memorias que involucran a coetáneos generacionalmente a los hijos/as pero sin vínculo sanguíneo con los desaparecidos. Asimismo, resulta interesante la decisión de la autora de no enmarcar estas narrativas en la noción de posmemoria (Hirsch, 2012), puesto que no se trata solamente de la transmisión transgeneracional de los pasados traumáticos. En términos 
generales, se destacan las diferencias entre el holocausto y el proceso argentino que impiden pensar procesos de transmisión similares así como los límites del concepto para analizar las producciones de artistas que exceden el lazo familiar con los desaparecidos. La investigadora no rechaza la totalidad del enfoque, pero si propone alternativas más flexibles que no encasillen al caso argentino en parámetros idénticos a los de posmemoria y que pongan el foco en lo característico del contexto nacional.

A partir de las reflexiones de Basile, es válido ampliar la indagación sobre las experiencias de los hijos/as y preguntarse ¿qué sucedió con los hijos/as de los obreros desaparecidos?, ¿con los que quedaron en institutos de menores?, ¿con los que vivieron con familias totalmente despolitizadas?, ¿con los que no fueron a la universidad?, ¿con los hijos/as que no militaron políticamente? Todas preguntas que la obra de Teresa Basile impulsa a resolver.

\section{Referencias bibliográficas}

Cueto Rúa, S. (2008). Nacimos en su lucha, viven en la nuestra. Identidad, justicia y memoria en la agrupación HIJOS-La Plata (Trabajo final de grado). Universidad Nacional de La Plata, La Plata Disponible en: http://www.memoria.fahce.unlp.edu.ar/tesis/te.427/te.427.pdf [Consultado el 1 de febrero de 2020].

Hirsch, M. (2012). The generation of Postmemory. Writing and Visual Culture After the Holocaust. New York: Columbia University Press.

Jelin, E. (2007). Víctimas, familiares y ciudadano/ as: las luchas por la legitimidad de la palabra. Cadernos Pagu (online), 29, 37-60. Disponible en: https://www.scielo.br/pdf/cpa/n29/a03n29.pdf [Consultado el 20 de febrero de 2020]

Daniela Pighin

Universidad Nacional de General Sarmiento danielapighin19@gmail.com

Para citar esta reseña:

Pighin, Daniela (2020): Reseña bibliográfica de: “Basile, T. (2019). Infancias. La narrativa argentina de HIJOS. Villa María: Eduvim. 297 pp." Anuario de la Escuela de Historia Virtual 17, 166-169. 